\title{
Nonword repetition in specific language impairment: More than a phonological short-term memory deficit
}

\author{
Lisa M. D. ARChibald \\ University of Western Ontario, London, Ontario, Canada \\ AND \\ Susan E. Gathercole \\ University of York, York, England
}

\begin{abstract}
The possible role of phonological short-term memory in the nonword repetition deficit of children with specific language impairment (SLI) was investigated in a study comparing serial recall and nonword repetition of sequences of auditorily presented CV syllables. The SLI group showed impairments in both serial recall and nonword repetition relative to typically developing children of the same age, however the SLI deficit in nonword repetition was greater and persisted even when differences on an independent measure of short-term memory were taken into account. These findings cannot be readily explained in terms of a sole deficit in short-term memory, and point instead to differences between the serial recall and nonword repetition paradigms as potential factors contributing to this disorder of learning.
\end{abstract}

The capacity to repeat a novel phonological form such as woogalamic is one of the most basic and important language abilities. Every word we now know was once unfamiliar to us, and was learned, in part, via such a repetition attempt. The evidence linking nonword repetition and language learning abilities is now extensive. In particular, individuals who perform poorly on nonword repetition typically struggle to learn the phonological form of language. The evidence for this is now extensive. Individual differences studies of typically developing samples of children have established highly specific links between nonword repetition and knowledge of vocabulary of both the native language (e.g., Gathercole \& Baddeley, 1989; Gupta, 2003) and foreign languages (e.g., Cheung, 1996; Masoura \& Gathercole, 1999). Children's nonword repetition abilities are also highly associated with the speed of learning the phonological forms of new words under experimental conditions that control exposure to the novel tokens, although not to nonphonological aspects of learning such as the acquisition of semantic features (e.g., Gathercole, Service, Hitch, Adams, \& Martin, 1999; Gupta, 2003). Finally, severe deficits of nonword repetition have been found to characterize several groups of children with particularly marked impairments of language learning, including individuals with specific reading disabilities (e.g., Snowling, 1983), Down's syndrome (e.g., Laws, 2004), and specific language impairment (SLI; e.g., Gathercole \& Baddeley, 1990).

The co-occurrence of deficits in nonword repetition and SLI in particular has now been extensively documented (see, e.g., Conti-Ramsden, 2003; Dollaghan \& Campbell, 1998; Edwards \& Lahey, 1998; Montgomery, 2004). SLI is a relatively common developmental condition in which a child fails to develop language at the typical rate despite normal general intellectual abilities, adequate exposure to language, and in the absence of hearing impairments. Affected children have the greatest problems in learning word forms and the grammatical structure of language, with acquisition of semantics and pragmatics relatively spared (Leonard, 1998). Current interest in nonword repetition and SLI was sparked principally by Gathercole and Baddeley's findings in 1990 that a group of children with SLI had impairments in repeating lengthy nonwords that were even greater in magnitude than the language deficits that formed the basis for their diagnosis. The nonword repetition impairment has subsequently been established in many independent studies to be a hallmark of SLI (see Roy \& Chiat, 2004, for review), and has been hailed both as a clinical indicator of SLI (Conti-Ramsden, 2003; Dollaghan \& Campbell, 1998) and as a phenotypic marker of the genetic basis for SLI (Bishop, North, \& Donlan, 1996) associated with abnormalities of chromosome 16q (SLI Consortium, 2004). The impairment is particularly compelling as it captures the language learning difficulties of individuals with SLI in a simple paradigm that mimics word learning.

The established links between nonword repetition and language learning has led to widespread interest in understanding the cognitive processes that underlie nonword repetition. Nonword repetition was first proposed as a

L. M. D. Archibald, larchiba@uwo.ca 
relatively pure index of phonological short-term memory (STM) capacity (Gathercole \& Baddeley, 1989, 1993). According to this view, repetition of nonwords requires more reliance on the temporary storage of phonological representations in STM than items such as words or digits because of the reduced availability of long-term lexical knowledge to support the unfamiliar phonological forms. It was further suggested that the nonword repetition deficit in SLI arises from an impairment of phonological STM (Gathercole \& Baddeley, 1990) such that limitations in storage capacity result in reduced repetition accuracy. Reports that children with SLI do indeed perform poorly also on more conventional serial recall measures of STM, such as digit and word span, are consistent with this position (e.g., Archibald \& Gathercole, 2006; Montgomery, 1995). Research with other populations also indicates that an impairment of STM does disrupt language learning. Experimental studies of normal adult participants have established that the learning of new words is impaired under experimental conditions known to disrupt phonological STM (e.g., Papagno \& Vallar, 1992). Furthermore, neuropsychological patients with acquired deficits in STM appear to be unable either to repeat nonwords or to learn the phonological forms of new words, despite retaining normal abilities to learn semantic associations (see, e.g., Baddeley $\&$ Wilson, 1993). Together, this evidence converges on the view that nonword repetition taps phonological STM, that STM mediates the phonological long-term learning of new words, and that at least some of the language learning difficulties associated with SLI may arise from an impairment of STM. On this basis, Baddeley, Gathercole, and Papagno (1998) proposed that the primary function of phonological STM is to support word learning.

One potential problem for the proposal that children with SLI have an impairment of STM and thus for the account of phonological STM as an important influence on language learning is that SLI deficits in nonword repetition tend to be more marked than those in standard serial recall measures of STM. For example, in a recent study of 20 children with SLI from 7 to 11 years in age, Archibald and Gathercole (2006) found that, whereas 14 of the children showed a deficit on measures of serial recall of digits and word lists, every child had a deficit in nonword repetition. Furthermore, the absolute magnitude of the deficits was greater for nonword repetition than serial recall, although the stimuli employed in these tasks differed substantially (i.e., in length, familiarity, and phonological properties). The discrepancy in the magnitude of the SLI deficits may reflect better memory for words than nonwords (see, e.g., Hulme, Maughan, \& Brown, 1991), which would convey an advantage to typically developing children with larger vocabularies (Snowling, Chiat, \& Hulme, 1991). Other factors such as poor phonological sensitivity (Bowey, 2001; Metsala, 1999) and impairments of speech-motor output processes (Sahlen, Reuterskiold-Wagner, Nettelbladt, \& Radeborg, 1999; Vance, Stackhouse, \& Wells, 2005) could also contribute to the greater deficits found in SLI for nonword repetition than serial recall.

The present study focuses on why nonword repetition provides such a strong predictor and discriminator of language learning ability, and in particular on whether nonword repetition is simply an index of STM capacity. School-age children with SLI and typically developing children of the same age completed a nonword repetition task and a more conventional STM task, serial recall which requires the immediate, ordered recall of items. The novel feature of the current work was the equivalence of the stimuli to be recalled in the two paradigms, consisting of sequences of nonword consonant-vowel (CV) syllables presented either in isolation for serial recall (e.g., fow . . . moy . . chee) or as a single coarticulated nonword for repetition (e.g., fowmoychee). Thus the syllabic content and nonword status of the sequences was the same in the two tasks and imposed an equivalent load on STM. The tasks, however, do differ in other ways that may influence repetition. STM demands may be greater in the serial recall condition due to the increased sequence duration resulting from the additional pauses inherent in the monosyllable lists. The longer duration of sequences in serial recall may also provide more perceptible syllables due to greater acoustic-phonetic salience, and opportunities for the use of verbal strategies such as rehearsal conveying an advantage to the typically developing group with ageappropriate language skills in the present study. In nonword repetition, the multisyllabic productions would incorporate coarticulatory and prosodic cues, which may potentially benefit recall. On the other hand, response accuracy may be reduced in nonword repetition as the greater output demands for more rapid and coarticulated speech gestures which may result in greater SLI decrements due to the potential presence of subtle speech motor impairments in this group (Goffman, 1999, 2004).

The present study provided a direct experimental test of the hypothesis that the nonword repetition deficit in SLI arises from an impairment of STM alone. If the severe impairment of nonword repetition characterizing children with SLI reflects solely an impairment of STM, the SLI group should show deficits relative to typically developing children to an equivalent extent in both nonword repetition and serial recall, or to a larger degree in serial recall due to the greater opportunities for trace decay. Differential employment of rehearsal strategies would also lead to disproportionate SLI deficits in serial recall. A finding that the SLI group is more impaired on nonword repetition would identify potential SLI deficits in factors additional to STM that differentiate the two paradigms.

\section{METHOD}

\section{Participants}

Participants were 13 children with SLI ( 8 males, 5 females), and 16 typically developing children of the same age, all of whom were native English speakers. The groups were closely matched in age: SLI, $M=$ 10 years, 5 months $(S D=1.77$, range $=7 ; 10-13 ; 0)$; control, $M=10$ years, 2 months $(S D=1.63$, range $=7 ; 6-13 ; 0)$. All participants obtained standard scores of 85 or greater on measures of nonverbal ability (Raven's Coloured Matrices; Raven, Court, \& Raven, 1986), and articulation (Test of Articulation 2; Goldman \& Fristoe, 2000). None of the children had a diagnosis of ADD/ADHD, autism spectrum disorder, or hearing impairment. None of the children participating in the control group were known to have histories of speech, language, or hearing problems, or any type of exceptional educational needs. 
The children in the SLI group were recruited from specialist units or schools, and the children participating in the control groups were recruited from a school with a similar socioeconomic intake to the schools attended by the SLI group. At the time of recruitment, 9-12 months prior to their participation in the present study, all of the children completed four standardized language measures, two receptive measures, the British Picture Vocabulary Scales-II (BPVSII; Dunn, Dunn, Whetton, \& Burley, 1997) and the Test for Reception of Grammar (TROG; Bishop, 1982), and two expressive measures, the Expressive Vocabulary Test (EVT; Williams, 1997), and the Recalling Sentences subtest of the Clinical Evaluation of Language Fundamentals-UK 3 (CELF; Semel, Wiig, \& Secord, 1995). All members of the SLI group performed at least $1.25 \mathrm{SD}$ below the mean on two of four of the language measures including one receptive measure (Records \& Tomblin, 1994), and all control children scored within $1.00 S D$ of the mean for their age on three of the language measures, including both receptive measures (BPVS-II and TROG). Performance on the Recalling Sentences subtest was not used as an exclusionary criterion for control participants because the task taps skills other than language (i.e., memory) that are of interest in the present study. In order to ensure that the language skills of the children in the present study remained consistent with the recruitment criteria, all participants completed an additional language measure at the time of the present study, the short form of the BPVS (Dunn et al., 1982). Descriptive statistics for all screening measures are provided in Table 1.

\section{Design and Materials}

All participants completed two experimental tasks, serial recall and nonword repetition. Order of presentation of the two tasks was counterbalanced, with 6 or 7 participants within each group completing serial recall first, and the remainder, nonword repetition first In each task, eight experimental trials preceded by two practice trials were presented at each of three syllable lengths - 3,4 , and $5 \mathrm{CV}$ syllables. The serial recall and nonword repetition lists were constructed from a pool of phonemes that excluded the eight consonants that are late acquired (Shriberg \& Kwiatkowski, 1994). As well, tense vowels were included so that the multisyllabic nonwords were produced with equal stress across syllables (Dollaghan \& Campbell, 1998), thereby minimizing prosodic differences across tasks. The resulting pool of $30 \mathrm{CV}$ syllables generated by combining 13 consonants and 8 vowels is shown in the Appendix. Twenty-four syllables were

Table 1

Descriptive Statistics for Screening Measures for All Groups

\begin{tabular}{|c|c|c|c|c|c|}
\hline \multirow[b]{2}{*}{ Test } & \multirow[b]{2}{*}{ Score } & \multicolumn{2}{|c|}{ SLI } & \multicolumn{2}{|c|}{ Control } \\
\hline & & $M$ & $S D$ & $M$ & $S D$ \\
\hline \multirow[t]{2}{*}{ Raven } & Raw & $25.69 \mathrm{a}$ & 5.01 & $28.44_{a}$ & 3.77 \\
\hline & Standard & $102.85_{\mathrm{a}}$ & 9.93 & $110.00_{\mathrm{a}}$ & 11.31 \\
\hline \multirow[t]{2}{*}{ GFTA-2 } & Raw & 5.38 & 2.22 & 0.44 & 1.50 \\
\hline & Standard & 92.23 & 2.98 & 103.44 & 5.23 \\
\hline \multirow[t]{2}{*}{ BPVS-II } & Raw & 66.54 & 13.26 & 98.85 & 19.39 \\
\hline & Standard & 76.85 & 9.61 & 103.94 & 12.22 \\
\hline \multirow[t]{2}{*}{ BPVS-sf } & Raw & 15.85 & 3.56 & 21.19 & 4.09 \\
\hline & Standard & 75.15 & 18.74 & 103.44 & 16.24 \\
\hline \multirow[t]{2}{*}{ TROG } & Raw & 11.85 & 2.48 & 17.44 & 1.79 \\
\hline & Standard & 77.54 & 7.67 & 107.00 & 11.26 \\
\hline \multirow[t]{2}{*}{ EVT } & Raw & 69.62 & 10.84 & 87.75 & 19.23 \\
\hline & Standard & 81.85 & 10.80 & 98.13 & 13.91 \\
\hline \multirow[t]{2}{*}{ Recalling Sentences } & Raw & 17.46 & 3.50 & 39.69 & 13.22 \\
\hline & Standard & 66.15 & 0.60 & 91.25 & 2.67 \\
\hline \multirow[t]{2}{*}{ Digit Recall } & Raw & 25.23 & 4.07 & 29.69 & 5.13 \\
\hline & Standard & 86.92 & 16.76 & 100.00 & 16.01 \\
\hline
\end{tabular}

Note - Raven, Raven's Coloured Matrices; GFTA-2, Goldman Fristoe 2: Test of Articulation; BPVS-II, British Picture Vocabulary Scale, 2nd ed; sf, short form; TROG, Test for Reception of Grammar; EVT, Expressive Vocabulary Test; for standard scores, $M=100, S D=15$. Means sharing a subscript in the same row are not significantly different according to the Tukey test of honestly significant differences $(p>.05)$. selected for use in the experimental trials. The remaining 6 syllables were employed in the practice trials only, with the exception of 1 syllable from the experimental pool that had to be used to construct the 5-syllable practice items in order to fulfill the criteria described below for sequence construction. The eight sequences at each list length were created by combining the syllables from the 24-syllable pool for the experimental tasks with the following constraints: no phonemes were repeated within a sequence; all syllables occurred at least once for each list length; each vowel occurred in each ordinal position at least once within each list length; all syllables occurred at least four times in different ordinal positions across all the items.

The experimental stimuli spoken by a native British adult female speaker were digitally recorded. In order to compare phoneme durations across the experimental tasks, the duration of consonants and vowels in all syllables, and the total duration for the nonword repetition stimuli were measured on an acoustic waveform. Consonant durations included closure, burst and aspiration, where applicable. Vowels were measured from onset to offset of voicing. In one-way ANOVAs performed as a function of task (nonword repetition, serial recall), no significant difference was found for consonants ( $p>.05$, $\eta_{\mathrm{p}}^{2}=.02$ ) whereas vowel durations were significantly longer in the monosyllables for serial recall than the multisyllable nonwords for nonword repetition ( $p<.001, \eta_{\mathrm{p}}^{2}=.42$ ) by $12 \mathrm{msec}$ on average.

All participants also completed one additional test of short-term memory, the Digit Recall subtest of the Working Memory Test Battery for Children (WMTB-C; Pickering \& Gathercole, 2001). For this task, a sequence of digits was presented that the child was required to recall in correct serial order. The digit lists were constructed randomly without replacement from the digits ranging from 1 to 9 , and were spoken at a rate of 1 digit/sec. Following three practice trials, a maximum of six lists of digits was presented beginning with two or three digits (depending on success in the practice trials) to a maximum of nine digits. List length was increased by one if the child recalled four lists at that length correctly. If the first four trials were correct, the child was credited with correct recall of all six lists at that length and the next list length commenced. Testing continued until three lists of a particular length were recalled incorrectly. The number of lists correctly recalled is scored, and standard scores calculated based on the published norms (Pickering \& Gathercole, 2001).

\section{Procedure}

The experimental tasks were completed in a single session in a quiet room in the child's school. Presentation of the experimental stimuli was controlled by a specialized computer program. For the serial recall task, the child was asked to listen to each sequence of sounds, and to repeat them in the same order at the end of the sequence. The syllable sequences were presented at the rate of one every $750 \mathrm{msec}$ for serial recall. For nonword repetition, the child was told that they would hear a made-up word and asked to repeat it back immediately. All responses were recorded digitally and phonetically transcribed by the first author. Accuracy was scored at the syllable level according to a strict serial order criterion, by which a syllable is only scored as correct if each phoneme is accurate, and in the correct order and ordinal position. The BPVS short form (Dunn et al., 1982) and Digit Recall subtest (Pickering \& Gathercole, 2001) were completed in a second session that followed within 1 month.

\section{RESULTS}

Performance of the participant groups on the serial recall and nonword repetition tasks is summarized in Table 2. Repetition accuracy was higher for nonword repetition than serial recall across groups. Within each task, accuracy declined sharply with increasing sequence lengths. The SLI group performed at lower levels than the control group on both tasks, although group mean differences were larger for nonword repetition. Performance 
Table 2

Number and Percentage of Syllables Correct at Each Item Length for Each Participant Group

\begin{tabular}{|c|c|c|c|c|c|c|c|c|}
\hline \multirow{3}{*}{$\begin{array}{l}\text { Task/Length } \\
\text { and Measure }\end{array}$} & \multicolumn{4}{|c|}{ SLI } & \multicolumn{4}{|c|}{ Control } \\
\hline & \multicolumn{2}{|c|}{ Raw Score } & \multicolumn{2}{|c|}{$\%$ Correct } & \multicolumn{2}{|c|}{ Raw Score } & \multicolumn{2}{|c|}{$\%$ Correct } \\
\hline & $M$ & $S D$ & $M$ & $S D$ & $M$ & $S D$ & $M$ & $S D$ \\
\hline \multicolumn{9}{|l|}{ Serial Recall } \\
\hline 3 syllables & 14.62 & 4.09 & 60.90 & 17.06 & 17.50 & 3.12 & 72.92 & 13.00 \\
\hline 4 syllables & 8.31 & 4.85 & 25.97 & 15.17 & 13.31 & 6.83 & 41.60 & 21.34 \\
\hline 5 syllables & 2.85 & 2.64 & 7.12 & 6.60 & 7.44 & 5.45 & 18.59 & 13.63 \\
\hline \multicolumn{9}{|c|}{ Nonword Repetition } \\
\hline 3 syllables & 16.00 & 4.53 & 66.67 & 18.87 & 21.06 & 2.65 & 87.76 & 11.02 \\
\hline 4 syllables & 12.54 & 7.32 & 39.18 & 22.88 & 20.44 & 5.39 & 63.87 & 16.85 \\
\hline 5 syllables & 8.54 & 4.67 & 21.35 & 11.66 & 11.31 & 4.51 & 28.28 & 11.28 \\
\hline
\end{tabular}

was very low for the five-syllable sequences with scores less than $30 \%$ correct for all conditions and groups. The data from these conditions were therefore excluded from further analysis. A rationalized arcsine transform function was used to convert all percentage scores into interval level data prior to statistical analysis (Studebaker, 1985).

An analysis of variance was performed on the percent of syllables correctly recalled by each child within the two participant groups as a function of task type (serial recall and nonword repetition) and list length (three and four syllables). All three main effects were highly significant: task $\left[F(1,27)=38.858, p<.001, \eta_{\mathrm{p}}^{2}=.59\right]$, reflecting greater recall accuracy for nonword repetition; length $[F(1,27)=$ $\left.263.797, p<.001, \eta_{\mathrm{p}}^{2}=.91\right]$, due to the decline in accuracy with increasing sequence length; group $[F(1,27)=11.267$, $\left.p<.005, \eta_{\mathrm{p}}^{2}=.29\right]$, with the control group performing at a superior level. Importantly, there was a significant interaction between task and group $[F(1,27)=4.837, p=$ $\left..037, \eta_{\mathrm{p}}^{2}=.15\right]$. Further exploration of this interaction term in ANOVAs performed on each task separately as a function of group established that while the scores of the SLI group were significantly lower than the age-match group in each case, the effect size was much greater for nonword repetition $\left[F(1,27)=13.420, p<.001, \eta_{\mathrm{p}}^{2}=.33\right]$ than serial recall $\left[F(1,27)=5.866, p=.022, \eta_{\mathrm{p}}^{2}=.18\right]$. Figure 1 presents the group means on both serial recall and nonword repetition collapsed across lengths. It is clear from this figure that although impairment occurred on both measures, the SLI deficit was greater for nonword repetition. The remaining terms were nonsignificant [length and group, $F(1,27)=0.347, p=.561, \eta_{\mathrm{p}}^{2}=.01$; task and length, $F(1,27)=0.615, p=.440, \eta_{\mathrm{p}}^{2}=.02$; task, length, and group, $\left.F(1,27)=0.029, p=.866, \eta_{\mathrm{p}}^{2}=.001\right]$.

A further set of analyses of covariances were performed on both the nonword repetition and serial recall data separately in order to determine if group differences in the present study are attributable to skills other than STM. In these analyses, digit recall raw score was entered as covariate. As expected, the SLI group scored significantly more poorly than the control group on digit recall $[F(1,27)=6.478$, $\left.p=.017, \eta_{\mathrm{p}}^{2}=.19\right]$, a widely accepted index of STM, (see Table 1). Digit recall raw score was highly correlated with repetition accuracy averaged across syllable lengths (3 and 4) for both serial recall, $[r=.624, p<.001]$, and nonword repetition, $[r=.621, p<.001]$. Findings of persistent group differences even when adjustments are made for differences in digit recall performance, therefore, would indicate that at least some of the group differences are attributable to factors other than STM.

Results of the ANCOVA performed on the nonword repetition data with digit recall entered as a single covariate revealed a significant main effect of group $[F(1,26)=$ $\left.5.918, p=.022, \eta_{\mathrm{p}}^{2}=.19\right]$. The main effect of group was not significant in the corresponding ANCOVA for serial recall $[F(1,26)=1.210, p=.281]$. It should be noted that a post hoc power analysis calculated for comparing two groups with a sample size of 29 and a single covariate revealed a power level of .83 for an effect size of .33 (that associated with nonword repetition in the one-way ANOVAs reported above), and .62 for the corresponding effect size for serial recall of .18 (Faul \& Erdfelder, 1992). Given the low power associated with the serial recall ANCOVA, a compromise power analysis that equates $\alpha$ and $\beta$ levels was completed in order to determine the critical $F$ value required to maintain low risk of Type I error and maximize power (Faul \& Erdfelder, 1992). Results revealed that when $\alpha=\beta=.16$, the test would have a power level of .83 to detect a difference, and the critical $F$ value would be 1.964 . Comparing this critical value to that observed for the serial recall ANCOVA reported above (1.210) provided further evidence that there was no significant group effect in serial recall once scores were adjusted for digit recall performance. It should be noted also that ANCOVAs were performed on each experimental task (nonword repetition or serial recall) with the other task entered as covariate. The main effect of group was significant for nonword repetition only (even when adjustments to the critical $F$ value were made to allow for increased power). Thus, whereas nonword repetition performance could account for group differences in serial recall, serial recall performance was insufficient to account for the poor performance of the SLI group on nonword repetition.

\section{DISCUSSION}

In this study, the performance of children with SLI and an age-matched control group were compared on nonword repetition and serial recall tasks in which matched sequences of syllables were presented auditorily for recall. The purpose of the study was to establish whether the nonword repetition deficits that characterize children with SLI are attributable solely to an impairment of phonological STM, as proposed by Gathercole and Baddeley (1990). If so, the deficits of the SLI group should be comparable in magnitude in both tasks. In line with previous reports (e.g., Edwards \& Lahey, 1998; Montgomery, 1995), the SLI group showed very substantial decrements on both paradigms. However, accuracy of nonword repetition was disproportionately impaired in the SLI group, and could not be accounted for by differences on an independent measure of STM or performance on serial recall. For both participant groups, nonword repetition was associated with more accurate repetition overall.

These findings indicate that the disproportionate SLI deficit in nonword repetition cannot be solely accounted 


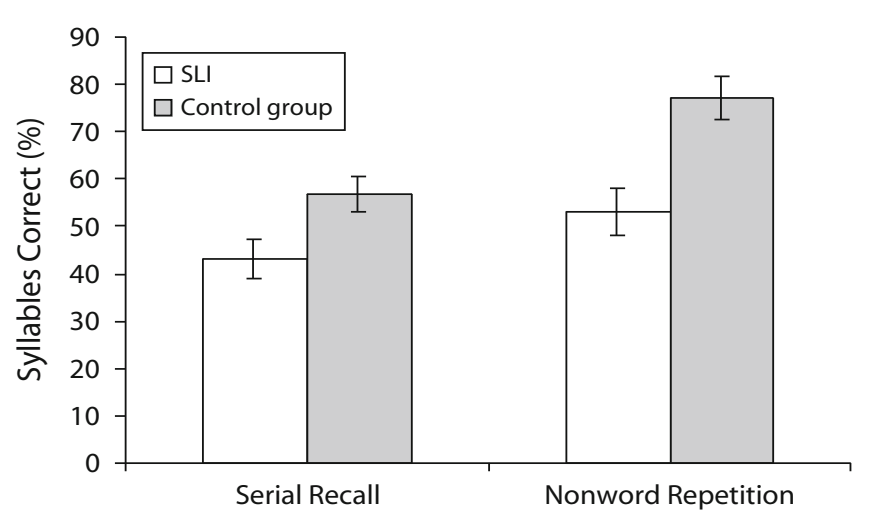

Figure 1. Mean percentage syllables correct, with standard error bars, on each repetition task for the SLI and control groups.

for by impairments in STM. This conclusion hinges on the supposition that the STM load of the two tasks in the present study was at least equivalent, or greater in the serial recall paradigm. Several aspects of the present results provide support for this interpretation. It is clear that both serial recall and nonword repetition provided excellent indices of STM; repetition accuracy decreased with increases in sequence length reflective of temporal decay (Baddeley, Thomson, \& Buchanan, 1975; Cowan, Saults, Winterowd, $\&$ Sherk, 1991), and both tasks were highly correlated with digit recall, a standard measure of STM. The less accurate repetition in serial recall by both participant groups, however, indicates that the STM load imposed by the longer overall duration of the monosyllable lists may have been greater in this paradigm. The children with SLI, however, were not impaired to an equivalent degree on both tasks nor differentially impaired on serial recall, which would have been the case if STM alone accounted for the deficits in this group. As well, SLI deficits persisted in nonword repetition and not serial recall even when scores were adjusted for differences in STM. The nonword repetition advantage also rules out other factors expected to benefit serial recall such as opportunities for rehearsal and acoustic-phonetic salience of list syllables as important determinants of group differences on these tasks. It should be noted that one other study has compared performance in nonword repetition and serial recall and found more accurate repetition in serial recall (Gupta, 2005), however that study employed real words in the serial recall condition (and nonwords formed from the concatenation of these words in the nonword repetition condition) resulting in a lexicality effect in serial recall (Hulme et al., 1991).

We propose that the disproportionate SLI deficit in nonword repetition is best explained in terms of the contribution to memory for unfamiliar syllable sequences of two factors: STM, and a further ability that is specific to the repetition of novel multisyllabic phonological forms. The SLI group in the present study appeared to have deficits in both of these: They scored at lower levels on all of the STM measures employed in this study. This finding is consistent with the suggestion that STM deficits may underlie some of the vocabulary learning difficulties in SLI (Baddeley et al., 1998). In addition, the SLI group appears to have a particular problem in a second area that manifested itself in nonword repetition. A nonword repetition advantage is clearly evident in Figure 1 for the typically developing group, but this benefit was less marked for the SLI group.

The results of this relatively small study clearly established that the disproportionate deficit in nonword repetition in the SLI group was not a consequence solely of STM. The priority now is to replicate these findings with a larger sample in order to allow for the examination of the precise nature of the SLI deficit in nonword repetition. Differences in the demands of serial recall and nonword repetition provide a useful starting point for identifying candidate processes and mechanisms. One possibility is the physical cues to underlying structure present in connected speech but not in individually presented syllables, which may account for the superior performance in nonword repetition in the present study. Such cues include prosody (Roy \& Chiat, 2004) and coarticulation (Nijland et al., 2002), both of which play important roles in the perception and retention of speech. It may be that children with SLI fail to capitalize on these cues, or at least fail to benefit to the same extent as typically developing children.

Another potential hypothesis relates to problems in processing stimuli with rapid and sustained rates of transmission (Tallal et al., 1996). It may be that the temporal processing of the more rapid multisyllabic forms in nonword repetition at input was particularly problematic for the children with SLI. An additional important factor may be the significant extra demands both on the planning and execution of speech-motor gestures imposed by the repetition of multisyllabic nonwords relative to a sequence of simple syllable forms (Vance et al., 2005). Systematic experimental examination of the influences of these factors on the nonword repetition deficit in SLI has the potential not only to illuminate core problems underlying this developmental learning disorder, but also to inform the development of programs of remediation and learning support to boost language learning abilities in affected children.

\section{AUTHOR NOTE}

This research was supported by a Bamford-Lahey Children's Foundation Scholarship awarded to the first author. The authors thank the children and staff of all of the participating schools for their cooperation, and Annabel Thorn for assistance in the development of the experimental stimuli and with technical aspects of this project. Correspondence concerning this article should be addressed to L. M. D. Archibald, Department of Psychology, University of Western Ontario, London, ON, N6A 5C2 Canada (e-mail: larchiba@uwo.ca).

\section{REFERENCES}

Archibald, L. M. D., \& Gathercole, S. E. (2006). Short-term and working memory in SLI. International Journal of Language \& Communication Disorders, 41, 675-693.

Baddeley A. D., Gathercole S. E., \& Papagno C. (1998). The phonological loop as a language learning device. Psychological Review, 105, 158-173.

Baddeley, A. D., \& Wilson, B. A. (1993). A developmental deficit in short-term phonological memory: Implications for language and reading. Memory, 1, 65-78.

BISHOP, D. V. M. (1982). Test for reception of grammar. London: Medical Research Council.

Bishop, D. V. M., NorTh, T., \& Donlan, C. (1996). Nonword repetition as a behavioural marker for inherited language impairment: Evidence 
from a twin study. Journal of Child Psychology \& Psychiatry, 37, 391-403.

Bowey, J. A. (2001). Nonword repetition and young children's receptive vocabulary: A longitudinal study. Applied Psycholinguistics, 22, 441-469.

Cheung, H. (1996). Nonword span as a unique predictor of secondlanguage vocabulary learning. Developmental Psychology, 32, 867-873.

Conti-Ramsden, G. (2003). Processing and linguistic markers in young children with specific language impairment. Journal of Speech, Language, \& Hearing Research, 46, 1029-1037.

Dollaghan, C., \& Campbell, T. F. (1998). Nonword repetition and child language impairment. Journal of Speech, Language, \& Hearing Research, 41, 1136-1146.

Dunn, L. M., Dunn, L. M., Whetton, C. W., \& Burley, J. (1997). The British Picture Vocabulary Scales (2nd ed.). Windsor, U.K.: NFER Nelson.

EDWARDS, J., \& LAHEY, M. (1998). Nonword repetitions of children with specific language impairment: Exploration of some explanations for their inaccuracies. Applied Psycholinguistics, 19, 279-309.

FAUL, F., \& ERDFELDER, E. (1992). GPOWER: A priori, post-hoc, and compromise power analyses for MS-DOS [Computer program]. Bonn: Bonn University, Department of Psychology.

Gathercole, S. E., \& Baddeley, A. D. (1989). Evaluation of the role of phonological STM in the development of vocabulary in children: A longitudinal study. Journal of Memory \& Language, 28, 200-213.

Gathercole, S. E., \& Baddeley, A. D. (1990). Phonological memory deficits in language disordered children: Is there a causal connection? Journal of Memory \& Language, 29, 336-360.

Gathercole, S. E., Service, E., Hitch, G., Adams, A. M., \& Martin, A. J. (1999). Phonological short-term memory and vocabulary development: Further evidence on the nature of the relationship. Applied Cognitive Psychology, 13, 65-77.

Goldman, R., \& Fristoe, M. (2000). Goldman Fristoe 2: Test of Articulation. Circle Pines, MN: American Guidance Service.

Gupta, P. (2003). Examining the relationship between word learning, nonword repetition, and immediate serial recall in adults. Quarterly Journal of Experimental Psychology, 65A, 1213-1236.

Gupta, P. (2005). Primacy and recency in nonword repetition. Memory, 13, 318-324.

Hulme, C., Maughan, S., \& Brown, G. D. A. (1991). Memory for familiar and unfamiliar words: Evidence for a long-term memory contribution to short-term memory span. Journal of Memory \& Language, 30, 685-701.

LAWS, G. (2004). Contributions of phonological memory, language comprehension, and hearing to expressive language of adolescents and young adults with Down's Syndrome. Journal of Child Psychology \& Psychiatry, 45, 1085-1095.

LEONARD, L. (1998). Children with specific language impairments. Cambridge, MA: MIT Press.

Masoura, E. V., \& Gathercole, S. E. (1999). Phonological short-term memory and foreign language learning. International Journal of Psychology, 34, 383-388.

McCormack, T., Brown, G. D. A., Vousden, J. I., \& Henson, R. N. A. (2000). Children's serial recall errors: Implications for theories of short-term memory development. Journal of Experimental Child Psychology, 76, 222-252.
Metsala, J. L. (1999). The development of phonemic awareness in reading disabled children. Applied Psycholinguistics, 20, 149-158.

MonTGOMERY, J. (1995). Sentence comprehension in children with specific language impairment: The role of phonological working memory. Journal of Speech \& Hearing Research, 38, 187-199.

Montgomery, J. (2004). Sentence comprehension in children with specific language impairment: Effects of input rate and phonological working memory. International Journal of Language \& Communication Disorders, 39, 115-134.

Nijland, L., Maasen, B., van der Meulen, S., Gabreëls, F., KraaiMAAT, F. W., \& Schreuder, R. (2002). Coarticulation patterns in children with developmental apraxia of speech. Clinical Linguistics \& Phonetics, 16, 461-483.

Papagno, C., \& Vallar, G. (1995). Verbal short-term memory and vocabulary learning in polyglots. Quarterly Journal of Experimental Psychology, 48A, 98-107.

Pickering, S. J., \& Gathercole, S. E. (2001). Working Memory Test Battery for Children. London: Psychological Corporation.

Raven, J. C., Court, J. H., \& Raven, J. (1986). Raven's Coloured Matrices. London: H. K. Lewis.

Records, N., \& Tomblin, J. B. (1994). Clinical decision making: Describing the decision rules of practicing speech-language pathologists. Journal of Speech \& Hearing Research, 37, 144-156.

Roy, P., \& ChiAT, S. (2004). A prosodically controlled word and nonword repetition task for 2- to 4-year-olds: Evidence from typically developing children. Journal of Speech, Language, \& Hearing Research, 4, 223-234.

Sahlen, B., Reuterskiold-Wagner, C., Nettelbladt, U., \& RadeBORG, K. (1999). Nonword repetition in children with language impairment-Pitfalls and possibilities. International Journal of Language \& Communication Disorders, 34, 337-352.

SCHWEIKERT, R. (1993). A multinomial processing tree model for degradation and redintegration in immediate recall. Memory \& Cognition, 21, 168-175.

Semel, E., WiIG, E., \& Secord, W. (1995). Clinical Evaluation of Language Fundamentals-UK 3. London: Psychological Corporation.

ShriberG, L. D., \& KwiatKowski, J. (1994). Developmental phonological disorders: I. A clinical profile. Journal of Speech \& Hearing Research, 37, 1100-1126.

SLI CONSORTIUM (2004). Highly significant linkage to the SLI1 locus in an expanded sample of individuals affected by Specific Language Impairment. American Journal of Human Genetics, 74, 1225-1238.

SNOWLING, M. J. (1983). The comparison of acquired and developmental disorders of reading. Cognition, 14, 105-118.

Snowling, M. [J.], Chiat, S., \& Hulme, C. (1991). Words, nonwords and phonological processes: Some comments on Gathercole, Willis, Emslie and Baddeley. Applied Psycholinguistics, 12, 369-373.

Tallal, P., Miller, S. L., Bedi, G., Byma, G., Wang, X., Nagarajan, S. S., ET AL. (1996). Language comprehension in language-learning impaired children improved with acoustically modified speech. Science, 271, 81-84.

Vance, M., Stackhouse, J., \& Wells, B. (2005). Speech-production skills in children aged 3-7 years. International Journal of Language \& Communication Disorders, 40, 29-48.

Williams, K. (1997). Expressive Vocabulary Test. Circle Pines, MN: American Guidance Service.

\section{APPENDIX}

Syllables Used to Construct Stimuli in Both Repetition Conditions

\begin{tabular}{|c|c|c|c|c|c|c|c|}
\hline \multicolumn{8}{|l|}{ Practice Trials } \\
\hline Experimental $T$ & & & & & & & \\
\hline /kai/ & /kəu/ & /dav/ & /poi/ & /tei/ & /ba/ & /gi// & $/ \mathrm{ku} /$ \\
\hline $\begin{array}{l}/ \mathrm{faI} / \\
/ \text { jai/ }\end{array}$ & $\begin{array}{l}\text { /vou/ } \\
/ \mathrm{t} \text { fəu// }\end{array}$ & $/ \mathrm{mav} /$ & $/ \mathrm{moI} /$ & $\begin{array}{l}\text { /ver/ } \\
/ \mathrm{t}\lceil\mathrm{e} /\end{array}$ & $\begin{array}{l}/ \mathrm{ta} / \\
/ \mathrm{da} /\end{array}$ & $/ \mathrm{t} \int \mathrm{j} / /$ & $\begin{array}{l}/ \mathrm{fu} / \\
/ \mathrm{vu} /\end{array}$ \\
\hline
\end{tabular}

(Manuscript received July 1, 2006; revision accepted for publication December 18, 2006.) 